\title{
SELEÇÃO DE CLONES-ELITE DE MANDIOCA DE MESA VISANDO A CARACTERÍSTICAS AGRONÔMICAS, TECNOLÓGICAS E QUÍMICAS $\left({ }^{1}\right)$
}

\author{
THIAGO FONSECA MEZETTE $\left({ }^{2}\right)$; CÁSSIA REGINA LIMONTA CARVALHO $\left({ }^{3 *}\right)$; \\ MARCELO ANTONIO MORGANO $\left({ }^{4}\right)$; MARTA GOMES DA SILVA $\left({ }^{4}\right)$; \\ ENIELUCE SANTOS BRITO PARRA $\left({ }^{4}\right)$; JOÃO MANOEL SANSEVERINO VERGANI GALERA $\left({ }^{2}\right)$; \\ TERESA LOSADA VALLE $\left({ }^{3}\right)$
}

\begin{abstract}
RESUMO
A mandioca (Manihot esculenta Crantz) é uma das culturas mais importantes na alimentação humana dos trópicos, principalmente para as populações de baixa renda. Este trabalho teve por objetivo avaliar e selecionar clones-elite de mandioca de mesa com relação aos aspectos químicos, agronômicos e tecnológicos. Foram avaliados 12 clones do Programa de Melhoramento Genético da Mandioca de Mesa do IAC, em comparação à variedade-testemunha IAC 576-70, quanto a parâmetros de produtividade de raízes, tempo de cozimento, compostos cianogênicos, carotenóides totais, $\beta$-caroteno, vitamina $\mathrm{A}$ e componentes minerais. Dez clones se destacaram pela alta produtividade. O tempo médio de cozimento foi elevado, de 43,8 minutos. Entre os clones, apenas no 66/99 observou-se teor de compostos cianogênicos $\left(160,1 \mathrm{mg}\right.$ eq. $\left.\mathrm{HCN} \mathrm{k^{-1 }}\right)$ acima do limite de segurança de consumo, valor igual a $100 \mathrm{mg}$ eq. HCN kg-1. No clone 108/00 notaram-se maiores teores de carotenóides totais, $\beta$-caroteno e vitamina A, respectivamente, iguais a 1108,1 $\mu \mathrm{g} 100 \mathrm{~g}^{-1}, 940,1 \mu \mathrm{g} 100 \mathrm{~g}^{-1}$ e 523 UI $100 \mathrm{~g}^{-1}$, superiores às médias da variedade-testemunha. Dois clones destacaram-se pelos valores superiores em $44 \%$ de zinco e $53 \%$ de ferro, quando comparados à variedade IAC 576-70. Ao considerar o tempo de cozimento, a alta produtividade e os baixos teores de compostos cianogênicos como características essenciais em uma variedade de mandioca para mesa e ressaltando o enfoque da biofortificação dos componentes mineriais, carotenóides e vitamina A, o genótipo mais promissor a se tornar uma variedade é o clone 265/97.
\end{abstract}

Palavras-chave: Manihot esculenta Crantz, produtividade, compostos cianogênicos, tempo de cozimento, melhoramento nutricional, carotenóides, vitamina A, componentes minerais.

\section{ABSTRACT \\ SELECTION OF SWEET CASSAVA ELITE-CLONES FOR AGRONOMICAL, TECHNOLOGICAL AND CHEMICAL CHARACTERISTICS}

Cassava (Manihot esculenta Crantz) is one of the most important crops for human nutrition in the tropics, especially for low-income populations. This study aimed at to evaluate and select elite clones of sweet cassava regarding to chemical, agronomic and technological aspects, twelve clones of Instituto Agronômico breeding program were compared to control variety IAC 576-70 as to yield of roots, cooking, time, cyanogen compounds, total carotenoids, $\beta$-carotene, vitamin $\mathrm{A}$ and mineral components. Ten clones showed high yields. Average cooking time was high, 43.8 minutes. Among clones, only 66/99 showed

$\left({ }^{1}\right)$ Recebido para publicação em 2 de abril de 2007 e aceito em 18 de fevereiro de 2009.

${ }^{2}$ ) Mestre em Agricultura Tropical e Subtropical pelo Instituto Agronômico (IAC), Campinas (SP).E-mail: thiagomezette@yahoo.com.br; joãogalera@gmail.com

$\left(^{3}\right)$ Instituto Agronômico (IAC), 13012-970 Campinas (SP). E-mail: climonta@iac.sp.gov.br (*) Autora correspondente; teresalv@iac.sp.gov.br

( $\left.{ }^{4}\right)$ Instituto de Tecnologia de Alimentos (ITAL), Av. Brasil, 2880, 13070-178 Campinas (SP). morgano@ital.sp.gov.br; martags@ital.sp.gov.br; eni@ital.sp.gov.br 
content of cyanogen compounds (160.1 mg eq. HCN kg-1) above the limit (100 mg eq. $\left.\mathrm{HCN} \mathrm{kg}^{-1}\right)$ for safety consumption. Clone $108 / 00$ presented the highest content of total carotenoids, $\beta$-carotene and vitamin A, respectively, $1108.1 \mu \mathrm{g} 100 \mathrm{~g}^{-1}, 940.1 \mu \mathrm{g} 100 \mathrm{~g}^{-1}$ and $523 \mathrm{IU} 100 \mathrm{~g}^{-1}$, higher than the control. Two clones showed zinc and iron content respectively $44 \%$ and $53 \%$ higher than the control variety. Considering yield, cooking, low content of cyanogens mineral components, carotenoids and vitamin A, clone $265 / 97$ is the most promising genotype as a potential new variety.

Key words: Manihot esculenta Crantz, productivity, cyanogens, cooking time, nutrition, carotenoids, vitamin A, mineral components.

\section{INTRODUÇÃO}

A mandioca (Manihot esculenta Crantz) é uma das culturas mais importantes na alimentação humana dos trópicos, principalmente para as populações de baixa renda. A produção mundial foi estimada pela FAO (2005), em 210 milhões de toneladas. Apenas uma pequena parte é utilizada na alimentação animal ou como matéria-prima para produtos industrializados que não se destinam à alimentação humana. No Brasil, a mandioca integra o cardápio em todas as regiões brasileiras, desde o período pré-colonial até os dias atuais. É consumida na forma de farinha de mandioca ou de derivados de amido ou, ainda, as raízes são processadas no âmbito doméstico e consumidas cozidas, fritas ou utilizadas para preparar pratos típicos. Neste caso, são chamadas de mandioca de mesa ou de uso culinário.

Variedades de mandioca de mesa destinadas à comercialização das raízes, além de bom desempenho agrícola exigido pelo produtor, como boa produtividade, resistência a pragas e doenças, uniformidade e padrão comercial das raízes e facilidade de práticas culturais, também devem atender às exigências sensoriais e tecnológicas do consumidor final, demonstrando sabor característico, textura macia e cozimento rápido. As características sensoriais seguem padrões regionais. No Estado de São Paulo, o padrão comercial é o da variedade IAC 576-70, que atende praticamente a $100 \%$ dos mercados de comercialização in natura e de congelados. São raízes cilíndricas, amarelas e de cozimento rápido (LORENZI e VALLE, 2002).

A mandioca é uma planta cianogênica, ou seja, produz glicosídeos cianogênicos, os quais liberam o radical cianeto $\left(\mathrm{CN}^{-}\right)$, que é altamente tóxico. Variedades com elevados teores destes compostos na polpa das raízes, além de riscos de envenenamento, têm sabor desagradável; por esse motivo, são chamadas de variedades bravas ou amargas na taxonomia popular. Variedades in natura, com sabor agradável, são chamadas doces ou mansas. MKUMBIRA et al. (2003) constataram que o sabor amargo é perceptível quando as concentrações de glicosídeos cianogênicos são superiores a 100-150 mg eq. de HCN $\mathrm{kg}^{-1}$ de massa fresca de raízes. Embora a concentração de compostos cianogênicos seja influenciada pelo ambiente, o principal determinante é a composição genética da variedade e, deste modo, é possível classificar as variedades em mansas e bravas (FUKUDA e BORGES, 1988; VALLE, 2004).

Outro fator que deve ser levado em consideração na seleção de genótipos destinados à mesa é a qualidade culinária das raízes. Existem diversos fatores de qualidade que devem ser considerados, mas os de maior importância são a textura, a plasticidade e a pegajosidade da massa cozida (PEREIRA et al., 1985). Existe uma forte correlação entre o tempo de cozimento e essas características, de modo que, quanto menor o tempo de cozimento, melhor a massa cozida. Portanto, a simples determinação do tempo de cozimento é uma segura avaliação indireta da qualidade de massa cozida (Pereira et al., 1985; Fukuda e Borges, 1988; Lorenzi, 1994).

As carências alimentares existentes em populações pobres ou mal nutridas causam problemas de saúde pública em todo o mundo, principalmente em países pobres e em desenvolvimento. Assim, atualmente, existe uma preocupação por parte dos melhoristas em obter novas variedades que agreguem alto valor nutricional (WeLCH e GrAhAm, 2002).

Em países subdesenvolvidos onde a mandioca é a base alimentícia, variedades ricas em nutrientes teriam grande vantagem, tanto pelo baixo custo de produção da cultura, quanto pelo suprimento das necessidades nutricionais da população.

As deficiências de micronutrientes, em especial de vitamina $\mathrm{A}$, têm merecido destaque, devido ao número crescente de evidências que comprovam seu impacto negativo na saúde de grupos de maior vulnerabilidade nutricional como: gestantes, recémnascidos e crianças na idade pré-escolar (RAMALHO et al., 2002). A obtenção de vitamina A na alimentação humana ocorre por duas maneiras: por meio do consumo de alimentos de origem animal cuja vitamina A já está pré-formada (os retinóides) e pelo consumo de alimentos de origem vegetal nos quais são constatados carotenóides pró-vitamínicos A (RONCADA, 1998). 
A presença de carotenóides em raízes de mandioca foi relatada pela primeira vez por Maravalhas, em 1964, apud ORTEGA-FLORES (1991), ao estudar variedades amazônicas, embora tenha constatado apenas a presença de $\beta$-caroteno. Penteado (1987) e OrTEGA-Flores (1991), avaliando os teores de carotenóides com atividade pró-vitamínica em variedades de mandioca do Estado de São Paulo, verificaram que os principais carotenóides foram o trans- $\beta$-caroteno e os seus isômeros, o neo- $\beta$-caroteno B (13-cis- $\beta$-caroteno) e o neo- $\beta$-caroteno U (9-cis- $\beta$ caroteno). Verificaram, também, que o cozimento promoveu uma diminuição da atividade próvitamínica A. IgLESIAS et al. (1997) afirmam que, apesar de existir uma correlação entre a cor amarela da polpa da raiz e a presença de carotenóides, análises qualitativa e quantitativa dessas substâncias devem ser realizadas, visto que nem todos os carotenóides de coloração amarela possuem atividade vitamínica.

A deficiência de minerais é outro grave problema de nutrição e saúde pública em todo o mundo e, principalmente, em países em desenvolvimento como o Brasil. A recente introdução da biofortificação pode, nesses casos, representar novo e importante item do sistema integrado, que visa à redução da deficiência de micronutrientes no mundo (ZANCUL, 2004). Os minerais Fe e Zn são os de maior importância nutricional para o ser humano, sendo considerados elementos essenciais (OMs, 2006). A carência do primeiro é a causa da anemia ferropriva e o segundo está ligado à resposta imune, além de ambos terem propriedades antioxidantes. Em mandioca, até o presente momento, somente o trabalho desenvolvido por CHÁvez et al. (2005) evidencia a composição mineral das raízes. Os resultados obtidos pelos autores demonstraram grande variabilidade entre os acessos avaliados, tanto para o teor de ferro quanto para o de zinco.

O objetivo deste trabalho foi avaliar clones de mandioca em processo de seleção pelo Programa de Melhoramento de Mandioca do Instituto Agronômico (IAC), quanto aos aspectos agronômicos e tecnológicos e, principalmente, quanto aos aspectos químicos, visando identificar clones que possam se tornar cultivares com características nutricionais diferenciadas.

\section{MATERIAL E MÉTODOS}

Foram avaliados 12 clones do Programa de Melhoramento Genético de Mandioca de Mesa do IAC, resultantes de, no mínino, seis ciclos de seleção, em que se priorizou resistência à bacteriose, características agronômicas de produção, padrão de raízes e arquitetura da parte aérea, coloração amarela da polpa das raízes e avaliação para teor de carotenóides totais (CARVALHO et al., 2005). Foi utilizada a variedade comercial IAC 576-70 como testemunha.

O estudo foi realizado no período de agosto de 2005 a julho de 2006, instalando-se um experimento em Engenheiro Coelho (SP), a $22^{\circ} 24 \mathrm{~S}$, $47^{\circ} 09 \mathrm{~W}$, com altitude de $637 \mathrm{~m}$, precipitação pluvial anual média de $1210 \mathrm{~mm}$, temperatura média anual de $22{ }^{\circ} \mathrm{C}$ e umidade relativa em torno de $75 \%$. Foi utilizado delineamento inteiramente casualizado com 13 tratamentos e número variável de repetições, com subamostragem dentro das parcelas experimentais. As parcelas foram constituídas de 4 linhas de 10 plantas por linha, no espaçamento de $1 \mathrm{~m} \times 1 \mathrm{~m}$. Foram avaliados a produtividade pela massa total de raízes e massa de raízes descarte (raízes não comerciais com massa inferior a $200 \mathrm{~g}$ ou mal formadas), os teores de matéria seca, compostos cianogênicos, carotenóides totais e pró-vitamínicos $\mathrm{A}$, tempo de cozimento e a composição mineral das raízes.

De cada parcela experimental foram selecionadas 13 raízes das consideradas comerciais, de onde foram retirados toletes do terço médio central com $10 \mathrm{~cm}$ de comprimento. Estes foram descascados e cortados longitudinalmente ao meio, selecionandose metade para as análises de carotenóides e compostos cianogênicos e metade para a avaliação do tempo de cozimento.

A extração e a dosagem dos compostos cianogênicos foram realizadas de acordo com metodologia aperfeiçoada por Essers et al. (1993), entretanto, aplicaram-se modificações no método de extração, descritas em Mezette (2007). Para cada repetição de campo foram analisadas duas subamostras, sendo avaliadas com duas repetições de laboratório, perfazendo o total de dezesseis repetições analíticas, e a média foi tida como conteúdo cianogênico da polpa crua das raízes.

O tempo de cozimento foi avaliado segundo o método exposto por Pereira et al. (1985) e o teor de matéria seca pelo método gravimétrico descrito por Carvalho et al. (1990).

Para a análise dos carotenóides, pesaram-se cerca de $10 \mathrm{~g}$ de polpa de cada parcela experimental, em duplicata. Para a quantificação de carotenóides totais, utilizou-se o método descrito por CARVALHO et al. (1990), empregando-se a espectrofotometria UV/ Vis (HITACHI U-2000) a $453 \mathrm{~nm}$. Nessas condições, a concentração de carotenóides totais foi expressa em $\beta$-caroteno, sendo os cálculos realizados utilizando o coeficiente de absorção do $\beta$-caroteno em éter de petróleo $\left(\mathrm{A}_{1 \mathrm{~cm}}{ }^{1 \%}=2592\right)$. 
A identificação e determinação dos carotenóides pró-vitamínicos e a quantificação do $\beta$-caroteno foram efetuadas por cromatografia líquida de alta eficiência. Foram retiradas e evaporadas com fluxo de nitrogênio, alíquotas das amostras usadas na determinação dos carotenóides totais, sendo posteriormente ressuspensas no sistema de fase móvel, composto por metanol e clorofórmio $(97: 3 \mathrm{v} / \mathrm{v})$. A separação cromatográfica dos pigmentos foi realizada em coluna de fase reversa Lichrospher100 RP-18 (12,5 mm de comprimento, $4 \mathrm{~mm}$ de diâmetro interno e recheada com partículas de $5 \mu \mathrm{m}$ ) (Merck, Alemanha), em sistema isocrático com vazão de

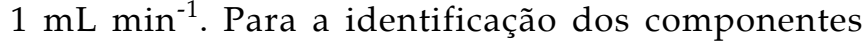
utilizou-se detector de arranjo de diodos (SPD-M6A, Shimadzu) e padronização externa. A concentração de vitamina A foi calculada a partir da concentração de $\beta$ caroteno presente nas amostras, considerando que $6 \mu \mathrm{g}$ de $\beta$-caroteno corresponde a 3,33 UI de atividade vitamina A (Anvisa RDC 269, de 22 de setembro de 2005).

Foi feita a determinação de componentes minerais das raízes cozidas e integrais (cruas) de cada clone, para verificar a composição mineral e a perda desses nutrientes quando submetidas ao processo de cozimento. As amostras de mandioca cozidas utilizadas foram as mesmas usadas nos testes de cozimento, as quais foram secas em estufa ventilada a $40{ }^{\circ} \mathrm{C}$, até atingirem massa constante. Para a determinação dos elementos minerais nas amostras integrais utilizaram-se as amostras secas oriundas das análises de matéria seca. Tanto as amostras cozidas quanto as integrais foram trituradas e armazenadas em sacos plásticos vedados em temperatura ambiente, para posterior avaliação. Cada clone teve suas amostras originadas de cada parcela experimental misturadas, resultando em uma única amostra para cada clone, sendo estas analisadas em triplicata. Para cada amostra foram pesados cerca de $5 \mathrm{~g}$ que foram incineradas a $450{ }^{\circ} \mathrm{C}$. Para a quantificação, empregou-se a técnica de Espectrometria de Emissão Óptica em Plasma Indutivamente Acoplado, modelo ICP 2000 (Massachusetts, USA). As condições de operação do equipamento foram: potência do plasma $0,9 \mathrm{~kW}$; gás refrigerante; gás auxiliar (Ar) a 7,0 $\mathrm{L} \mathrm{min}^{-1}$; vazão da amostra de $2,1 \mathrm{~mL} \mathrm{~min}^{-1}$; altura de observação vertical (acima da bobina de indução) de $19 \mathrm{~mm}$ e pressão do nebulizador (nebulizador babyton) de 3 bar. Os comprimentos de onda (nm) usados para determinação dos minerais foram: $\mathrm{K}=766,49 ; \mathrm{P}=178,28 ; \mathrm{Mg}=279,08$; $\mathrm{Ca}=317,93 ; \mathrm{Na}=539,59 ; \mathrm{Zn}=213,86 ; \mathrm{Fe}=259,94$; $\mathrm{Mn}=257,61 ; \mathrm{Ba}=493,41 \mathrm{e} \mathrm{Cu}=324,75$ (AOAC, 2005).

Os resultados foram submetidos à análise de variância, considerando-se o modelo de subamostragem e as médias dos tratamentos comparadas pelo teste de Tukey a 5\% de probabilidade. Para a análise estatística foi utilizado o software SAS, versão 8.0.

\section{RESULTADOS E DISCUSSÃO}

A produtividade média dos clones empregados no experimento foram de $23,14 \mathrm{t} \mathrm{ha}^{-1}$ (Tabela 1), considerada bastante alta, quando comparada com a produção média de mandioca de mesa no Estado de São Paulo, que é de aproximadamente $15 \mathrm{t} \mathrm{ha}^{-1}$, ao utilizar a variedade IAC 576/70. Portanto, os clones avaliados tiveram condições ambientais de expressar a capacidade produtiva. Observa-se na tabela 1 que a produtividade de raízes dos clones avaliados variou significativamente. Dez clones se destacaram pela boa produtividade, não diferindo estatisticamente da variedade-testemunha, e apenas os clones 66/99 e 33/ $00\left(15,32\right.$ e 15,59 $\left.\mathrm{t} \mathrm{ha}^{-1}\right)$ tiveram produtividade inferior.

Em relação às raízes descartadas, foi possível confirmar uma das razões que tornaram a variedade IAC 576-70 tão popular, visto que o percentual de raízes descartadas foi considerado bastante baixo. LORENZI (2003) afirma que a utilização da variedade IAC 576-70 diminuiu em 10\% os descartes na colheita. Embora para os clones as porcentagens de descarte tenham sido maiores, apenas dois (66/99 e 33/00) deles tiveram produção comercial estatisticamente inferior à da testemunha.

Tabela 1. Valores médios de produção total de raízes (PRT), produção de raízes comerciais (PRC) e porcentagem de descarte de raízes da variedade IAC 576-70 e de doze clones de mandioca de mesa, colhidos aos 254 dias após o plantio em Engenheiro Coelho (SP), 2006

\begin{tabular}{|c|c|c|c|}
\hline Clone & PRT & PRC & Descarte \\
\hline & \multicolumn{2}{|c|}{$\mathrm{t} \mathrm{ha}^{-1}$} & $\%$ \\
\hline IAC 576-70 & $27,52 a^{1}$ & $23,83 \mathrm{a}$ & 15,48 \\
\hline $265 / 97$ & $17,90 \mathrm{ab}$ & $14,65 \mathrm{ab}$ & 22,18 \\
\hline $290 / 97$ & $27,53 \mathrm{a}$ & $23,00 \mathrm{ab}$ & 19,70 \\
\hline $66 / 99$ & $15,32 \mathrm{~b}$ & $12,22 \mathrm{~b}$ & 25,29 \\
\hline $16 / 00$ & $27,10 \mathrm{a}$ & $22,10 \mathrm{ab}$ & 22,53 \\
\hline $27 / 00$ & $22,62 \mathrm{ab}$ & $17,77 \mathrm{ab}$ & 27,29 \\
\hline $113 / 00$ & $21,22 \mathrm{ab}$ & $17,90 \mathrm{ab}$ & 18,55 \\
\hline $108 / 00$ & $28,47 \mathrm{a}$ & $24,27 \mathrm{a}$ & 17,43 \\
\hline $33 / 00$ & $15,59 \mathrm{~b}$ & $12,07 \mathrm{~b}$ & 29,41 \\
\hline $28 / 00$ & $28,00 \mathrm{a}$ & $20,95 \mathrm{ab}$ & 33,65 \\
\hline $109 / 00$ & $20,29 \mathrm{ab}$ & $16,42 \mathrm{ab}$ & 23,63 \\
\hline $56 / 99$ & $22,42 \mathrm{ab}$ & $19,25 \mathrm{ab}$ & 16,47 \\
\hline $105 / 00$ & $25,90 \mathrm{ab}$ & $20,65 \mathrm{ab}$ & 25,52 \\
\hline Média geral & 23,14 & 18,98 & - \\
\hline CV (\%) & 16,12 & 20,47 & - \\
\hline
\end{tabular}

Médias seguidas de pelo menos uma mesma letra na coluna não diferem entre si, pelo teste de Tukey, a 5\% de probabilidade. 
O tempo de cozimento foi elevado (Tabela 2), em média, 43,8 minutos. O tempo médio de cozimento da variedade IAC 576-70 foi de 35,8 minutos e está acima do obtido em outros testes realizados pelo IAC, os quais normalmente são de 20 a 25 minutos; em condições ótimas o cozimento é atingido em 15 minutos (VALLE, 2007 - comunicação pessoal) $\left({ }^{6}\right)$. Outros autores verificaram valores inferiores: 25,5 minutos obtidos por BorGes et al. (2002), 29,0 minutos por LoRENZI (1994) e 25,8 minutos por RiMOLDI et al. (2006). Portanto, apesar de as condições ambientais terem sido favoráveis para a produtividade, o tempo de cozimento ficou aquém do ponto ótimo. Os clones 16/00,27/00, 108/00 e 109/00 eram de textura rígida e o cozimento não foi bom, sendo, possivelmente, inaptos para variedades de mesa.

LoRENZI (1994), avaliando o tempo de cozimento, observou que este pode ser prolongado pelo tipo de solo, de modo que solos menos férteis produzem raízes com cozimento mais prolongado ou simplesmente não cozinham. A variância média entre amostras (sete raízes) no presente artigo, ou seja, a diferença de tempo de cozimento entre raízes do mesmo clone e da mesma parcela foi de 18,25 minutos ${ }^{2}$ e a variância média entre parcelas foi de 16,93 minutos $^{2}$, evidenciando que as raízes são heterogêneas, fato já descrito por LoRENZI (1994). Assim, faz-se necessário trabalhar com várias raízes de uma mesma parcela para caracterizar o tempo de cozimento.

A variação do teor de glicosídeos cianogênicos foi altamente significativa entre os genótipos avaliados (Tabela 2). A média geral de 53,3 mg eq. $\mathrm{HCN} \mathrm{kg}{ }^{-1}$ foi superior ao da variedade testemunha $(30,9 \mathrm{mg}$ eq. $\mathrm{HCN}$ $\left.\mathrm{kg}^{-1}\right)$, mas dentro do limite de segurança proposto por LORENZI et al. (1993) (100 mg eq. HCN kg$\left.{ }^{-1}\right)$, amplamente utilizado para determinar se uma variedade é apta ou não para o consumo. Observa-se no clone 66/99 alto teor de $\mathrm{HCN}\left(160,1 \mathrm{mg}\right.$ eq. $\left.\mathrm{HCN} \mathrm{k^{-1 }}\right)$, não sendo apto para o consumo como variedade de mandioca de mesa. Em todos os outros clones havia teores dentro do limite proposto por LoRENZI et al. (1993). O valor médio observado na variedade padrão IAC 576-70 foi inferior aos valores constatados em outros trabalhos, como o de Aguiar (2003), cujos resultados variaram de 68,5 a $117,3 \mathrm{mg}$ eq. HCN kg${ }^{-1}$, em função do tempo de colheita. Resultados verificados no IAC para esta cultivar têm variações entre 30 e $120 \mathrm{mg}$ eq. de $\mathrm{HCN} \mathrm{kg}^{-1}$ (CARVALHO, 2007 - comunicação pessoal) $\left({ }^{7}\right)$. Portanto, é necessário que os clones sejam avaliados em outros locais, a fim de se estimar a estabilidade do teor de compostos cianogênicos.

$\left(^{6}\right)$ VALLE, T.L. Instituto Agronômico (IAC), Campinas (SP).

(7) Carvalho, C.R.L. Instituto Agronômico (IAC), Campinas.
Tabela 2. Valores médios do tempo de cozimento (TC) e teor de glicosídeos cianogênicos da variedade IAC 57670 e de doze clones de mandioca de mesa, colhidos aos 254 dias após o plantio em Engenheiro Coelho (SP), 2006

\begin{tabular}{lcc}
\hline \multirow{2}{*}{ Genótipo } & TC & Glicosídeos cianogênicos \\
\cline { 2 - 3 } IAC 576-70 & min. & mg eq. HCN kg \\
\hline $265 / 97$ & $34,7 \mathrm{bcd}$ & $30,9 \mathrm{c}$ \\
$290 / 97$ & $41,6 \mathrm{abcd}$ & $27,8 \mathrm{c}$ \\
$66 / 99$ & $45,4 \mathrm{abc}$ & $160,1 \mathrm{bc}$ \\
$16 / 00$ & $51,4 \mathrm{a}$ & $40,6 \mathrm{bc}$ \\
$27 / 00$ & $51,6 \mathrm{a}$ & $42,4 \mathrm{bc}$ \\
$113 / 00$ & $47,9 \mathrm{ab}$ & $57,0 \mathrm{bc}$ \\
$108 / 00$ & $52,0 \mathrm{a}$ & $33,5 \mathrm{c}$ \\
$33 / 00$ & $36,5 \mathrm{bcd}$ & $32,2 \mathrm{c}$ \\
$28 / 00$ & $29,4 \mathrm{~d}$ & $70,7 \mathrm{~b}$ \\
$109 / 00$ & $51,3 \mathrm{a}$ & $45,7 \mathrm{bc}$ \\
$56 / 99$ & $41,0 \mathrm{abcd}$ & $55,2 \mathrm{bc}$ \\
$105 / 00$ & $34,7 \mathrm{~cd}$ & $46,4 \mathrm{bc}$ \\
\hline Média geral & 43,8 & 53,3 \\
CV (\%) & 9,75 & 5,24 \\
\hline
\end{tabular}

Médias seguidas de pelo menos uma mesma letra na coluna não diferem entre si, pelo teste de Tukey, a $5 \%$ de probabilidade.

Levando-se em consideração que os clones aqui avaliados são originados do cruzamento entre variedades com baixos teores de compostos cianogênicos, o aparecimento de um genótipo com alto teor dessas substâncias pode ser explicado pelo fato de o caráter ser de herança quantitativa, como foi observado por VAlle et al. (2004).

Esses autores, analisando o conteúdo cianogênico em progênies de mandioca originadas do cruzamento de variedades mansas e bravas, verificaram que a segregação transgressiva do caráter permite o aparecimento de variedades bravas em cruzamentos que envolvem mandiocas com baixo potencial cianogênico.

A análise da variância dentro de amostras foi de 7,81 (mg eq. de HCN kg$\left.{ }^{-1}\right)^{2}$, bastante inferior ao efeito residual causado pelo ambiente entre amostras do mesmo clone, igual a 256,97 (mg eq. de $\left.\mathrm{HCN} \mathrm{kg}{ }^{-1}\right)^{2}$, evidenciando que apenas uma amostra é o suficiente para caracterizar a parcela. Assim, pode ser mais produtivo avaliarem-se mais repetições de clones no campo do que mais subamostras da mesma parcela. 
O teor de matéria seca dos clones e o resumo da análise da variância estão relacionados na tabela 3. O clone $290 / 97$ foi o de maior porcentagem de matéria seca $(44,25 \%)$ e o clone $16 / 00$, o de menor $(37,87 \%)$. A média geral, $40,98 \%$, foi bem próxima à média obtida por CARvalho et al. (2005), de 39,80\% quando se realizou a primeira avaliação desses clones.

As médias dos teores de carotenóides totais, $\beta$-caroteno e vitamina A estão descritas na tabela 3. O clone 108/00 proporcionou maior teor de carotenóides totais, em torno de $1108,1 \mu \mathrm{g} 100 \mathrm{~g} \mathrm{~g}^{-1}$, muito superior à média da variedade-testemunha, para a qual se obteve o conteúdo de $360,0 \mu \mathrm{g} 100 \mathrm{~g}^{-1}$. Pode-se observar um grupo de clones que não diferem estatisticamente da testemunha IAC 576-70 e um segundo grupo com valores bastante superiores. Este segundo grupo ainda pode ser subdividido em clones que não diferem estatisticamente do clone 108/00 $(265 / 97,27 / 00$ e $56 / 99)$ e os clones $16 / 00$ e $33 / 00$ com valores inferiores, mas com o dobro do conteúdo da variedade-testemunha.

Ao comparar os valores de carotenóides totais obtidos com os descritos por CHÁvez et al. (2005), quando avaliaram mais de 2 mil acessos do banco de germoplasma do Centro Internacional de Agricultura Tropical (CIAT) da Colômbia, pode se observar que os teores de carotenóides totais dos genótipos aqui avaliados estão dentro do intervalo obtido pelos

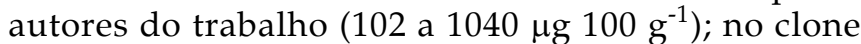
108/00 constatou-se valor maior que o limite superior deste intervalo. Porém, os clones aqui avaliados não são acessos de banco de germoplasma, e sim, genótipos-elite, previamente selecionados para características agronômicas desejáveis, portanto, com grande potencial para se tornaram uma variedade.

Com relação aos dados de $\beta$-caroteno (Tabela 3 ), o clone 108/00 foi o de maior teor, 940,1 ìg $100 \mathrm{~g}^{-1}$, e o clone $28 / 00$ o de menor valor $\left(130,2\right.$ ìg $\left.100 \mathrm{~g}^{-1}\right)$. Não foi feita análise de variância para $\beta$-caroteno, pois, para a determinação dos pigmentos, as amostras coletadas em cada parcela foram misturadas, compondo assim apenas uma amostragem por clone avaliado. Esse fato se justifica por se tratar de análises com elevado custo, além de já terem sido feitas análises desses clones, com repetições, em outro experimento (CARVALHO et al, 2005).

Um aspecto que deve ser levado em consideração é a atividade vitamínica dos carotenóides, sendo o $\beta$-caroteno o que de maior atividade. As estruturas dos carotenóides próvitamínicos lhes conferem diferentes capacidades de conversão à vitamina A (CARVALHO, 1996).

Tabela 3. Teores de matéria seca (MS), carotenóides totais, $\beta$-caroteno, porcentagem de $\beta$-caroteno e vitamina A, em raízes frescas da variedade IAC 576-70 e de doze clones de mandioca de mesa, colhidos aos 254 dias após o plantio em Engenheiro Coelho (SP), 2006

\begin{tabular}{|c|c|c|c|c|c|}
\hline Clone & MS & Carotenóides totais & $\beta$-caroteno & $\beta$-caroteno & Vit. A \\
\hline & $\%$ & \multicolumn{2}{|c|}{$\mu \mathrm{g} 100 \mathrm{~g}^{-1}$} & $\%$ & UI $100 \mathrm{~g}^{-1}$ \\
\hline IAC 576-70 & $43,58 \mathrm{ab}$ & $360,0 \mathrm{c}$ & 286,8 & 79,7 & 160 \\
\hline $265 / 97$ & $38,58 \mathrm{bcd}$ & $953,5 \mathrm{ab}$ & 717,9 & 76,7 & 400 \\
\hline $290 / 97$ & $44,25 \mathrm{a}$ & $380,5 \mathrm{c}$ & 266,0 & 69,9 & 147 \\
\hline $66 / 99$ & $40,56 \mathrm{abcd}$ & $428,7 \mathrm{c}$ & 412,6 & 96,2 & 230 \\
\hline $16 / 00$ & $37,87 \mathrm{~d}$ & $849,1 \mathrm{~b}$ & 798,7 & 94,1 & 443 \\
\hline $27 / 00$ & $41,83 \mathrm{abcd}$ & $973,8 \mathrm{ab}$ & 814,7 & 93,7 & 453 \\
\hline $113 / 00$ & $42,40 \mathrm{abcd}$ & $411,0 \mathrm{c}$ & 290,9 & 70,8 & 160 \\
\hline $108 / 00$ & $38,72 \mathrm{~cd}$ & $1108,1 \mathrm{a}$ & 940,1 & 84,8 & 523 \\
\hline $33 / 00$ & $39,72 \mathrm{abcd}$ & $759,7 \mathrm{~b}$ & 425,2 & 56,0 & 236 \\
\hline $28 / 00$ & 40,72 abcd & $329,5 \mathrm{c}$ & 130,2 & 39,5 & 73 \\
\hline $109 / 00$ & $37,92 \mathrm{~d}$ & $420,9 \mathrm{c}$ & 412,2 & 97,9 & 230 \\
\hline $56 / 99$ & $43,34 \mathrm{abc}$ & $891,3 \mathrm{ab}$ & 413,9 & 46,4 & 23 \\
\hline $105 / 00$ & 42,17 abcd & $349,2 \mathrm{c}$ & 303,1 & 86,8 & 170 \\
\hline Média geral & 40,98 & 641,85 & 477,85 & 74,4 & 265 \\
\hline CV (\%) & 2,40 & 8,78 & - & - & - \\
\hline
\end{tabular}

Médias seguidas de pelo menos uma mesma letra na coluna não diferem entre si, pelo teste de Tukey, a $5 \%$ de probabilidade.

** significativo a $1 \%$ de probabilidade. 


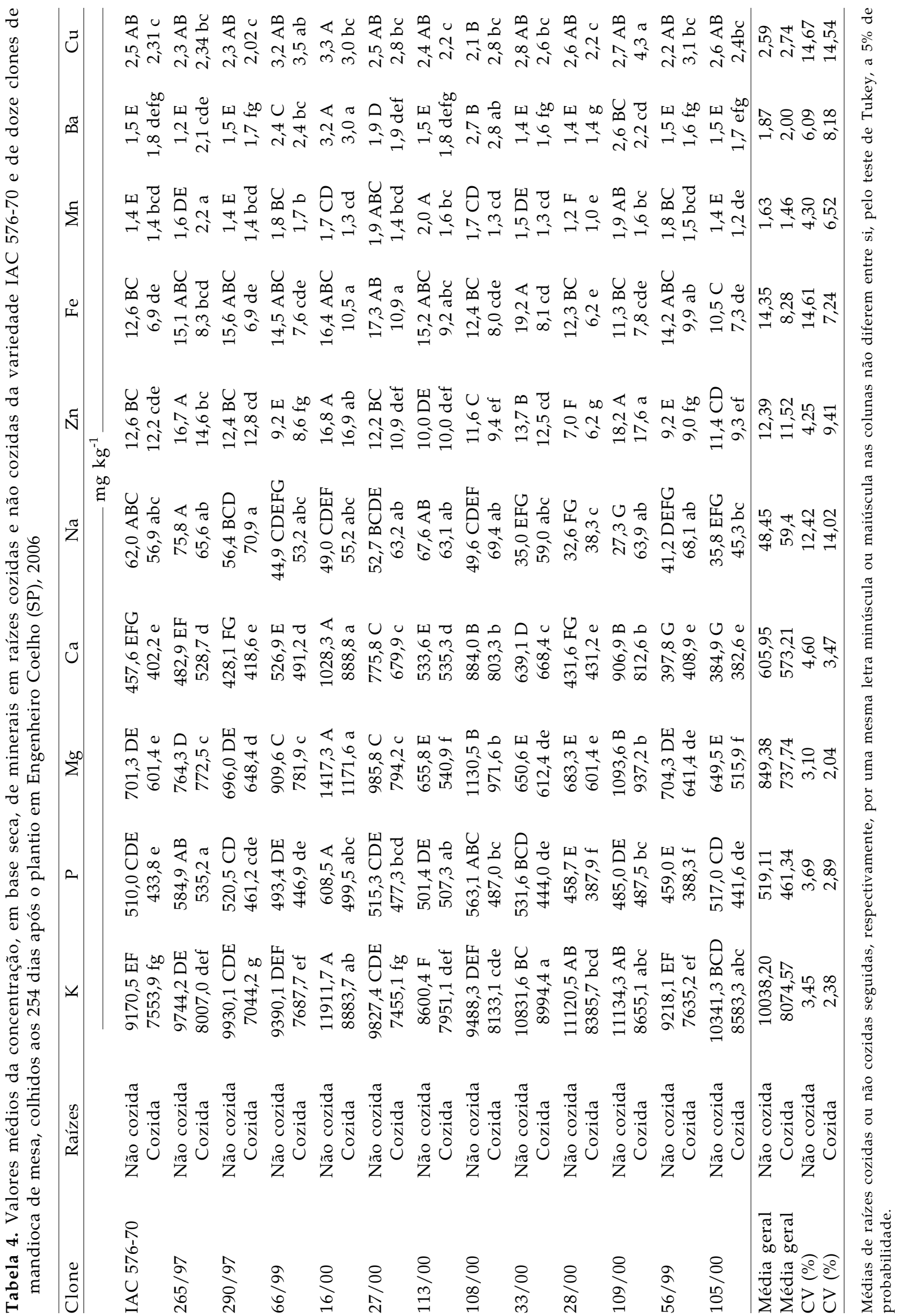


A estrutura mais importante é a do $\beta$-caroteno que possui $100 \%$ de atividade vitamínica $\mathrm{A}$, ou seja, a totalidade de $\beta$-caroteno é convertida em vitamina A (Bauernfeind, 1972 apud Carvalho, 1996). Possivelmente, muitos dos acessos avaliados por CHÁvez et al. (2005) não têm atividade vitamínica ou esta é reduzida. Todos os clones avaliados possuem o $\beta$-caroteno, como carotenóide predominante, com exceção dos clones 33/00, 28/00 e 56/99 que tiveram um percentual aproximado de $40 \%$ a $60 \%$. Considerando as necessidades diárias de vitamina A em segmentos populacionais (crianças $=2,4 \mathrm{mg}$; adultos $=3,5 \mathrm{mg}$ e mulheres lactantes $=5,0 \mathrm{mg}$ ), verifica-se que os clones deste trabalho podem ser considerados como fonte desse nutriente, visto que o consumo de $100 \mathrm{~g}$ de raiz do clone 108/00 (genótipo com maior teor de $\beta$-caroteno, 940,1 $\mu \mathrm{g} 100 \mathrm{~g}^{-1}$ ), mesmo após o cozimento e perda de parte dos carotenóides, supre grande parte das necessidades diárias de um indivíduo (AMBRósIo, 2006).

Na tabela 4, estão descritos os resultados da avaliação dos minerais, em base seca, constatados em raízes frescas e cozidas, evidenciando a perda de nutrientes durante o processo de cozimento, com exceção dos minerais sódio $(\mathrm{Na})$, bário $(\mathrm{Ba})$ e cobre $(\mathrm{Cu})$, com aumento em grande parte dos clones analisados, o que pode ser explicado por uma possível contaminação durante o processamento ou mesmo pela diferenciação de amostragem das raízes. Durante o cozimento, a média total de perda dos elementos foi de $15 \%$. O ferro (Fe) foi o elemento com a maior perda durante o processo de cozimento, cerca de $42 \%$ e o cálcio (Ca), o de menor perda, cerca de $5 \%$. Entre os clones, o que perdeu mais minerais durante o cozimento foi o $16 / 00$ (22\%) e o que perdeu menos foi o $56 / 99$ (14\%).

Verificou-se uma variação significativa entre os clones quanto aos teores de todos minerais, tanto nas amostras cozidas quanto nas não cozidas. Variação também observada em trabalho desenvolvido por CHÁvez et al. (2005), em que foram avaliados 600 acessos de banco de germoplasma somente na forma fresca.

Os resultados médios, em base seca, para os minerais $\mathrm{Fe}$ e $\mathrm{Zn}$ obtidos neste trabalho foram de aproximadamente $14 \mathrm{e} 12 \mathrm{mg} \mathrm{kg}^{-1}$ respectivamente. Os clones 265/97, 16/00 e 109/00 contêm mais $\mathrm{Zn}$ do que a testemunha, $33 \%$ a $44 \%$ a mais quando crus. O clone $33 / 00$ foi superior à testemunha quanto ao teor de Fe com um percentual de aumento de $53 \%$ quando cru. Estes aumentos, apesar da vantagem considerável, estão muito aquém do potencial da espécie em conter esses minerais. CHÁvez et al. (2005) identificaram variedades com $230 \mathrm{mg} \mathrm{kg}^{-1}$ de Fe e
$37,52 \mathrm{mg} \mathrm{kg}^{-1}$ de $\mathrm{Zn}$ ao analisarem 600 genótipos do banco de germoplasma do CIAT, na Colômbia.

A perda dos minerais $\mathrm{Fe}$ e $\mathrm{Zn}$ durante o cozimento da variedade-testemunha foi de apenas $4 \%$ para $\mathrm{Zn}$ e $46 \%$ para Fe. Entre os clones, aquele com menor perda de Fe foi o clone 56/99, cerca de 31\%, bem inferior à perda da variedade-testemunha. Não se observou perda de Zn no clone 113/00.

\section{CONCLUSÕES}

1. Após comparações agronômicas, tecnológicas e químicas dos clones avaliados, constata-se que há clones com teores de carotenóides e vitamina A bastante superiores ao da variedade comercial e com alta produtividade (108/00, 265/97 e 16/00).

2. Os clones com melhor tempo de cozimento são 28/00, 265/97, 105/00 e 33/00. Apenas no clone $66 / 99$ o teor de composto cianogênico é superior ao limite estabelecido, portanto, inapto para o consumo in natura.

3. Levando-se em consideração que tempo de cozimento, alta produtividade e baixos teores de compostos cianogênicos são características essenciais em uma variedade de mandioca para mesa e, tendo em vista que o objetivo do trabalho foi selecionar genótipos com altos teores de carotenóides e vitamina A, o clone 265/97 é o mais promissor para se tornar uma variedade.

\section{REFERÊNCIAS}

ANVISA. RDC 269, de 22 de setembro de 2005. Disponível em $<$ http:/ / e-legis.anvisa.gov.br/leisref / public / showAct.php?id=18828\&word $>$. Acesso em 3 de março de 2007.

AGUIAR, E.B. Produção e qualidade de mandioca de mesa (Manihot esculenta Crantz) em diferentes densidade populacionais e épocas de colheita. 2003. 103f. Dissertação (Mestrado em Agricultura Tropical e Subtropical) - Instituto Agronômico, Campinas (SP).

AMBRÓSIO, C.L.B.; CAMPOS, F.A.C.S.; FARO, Z.P. Carotenóides como alternativa contra a hipovitaminose A. Revista de Nutrição, v.19, n.2, p.233-243, 2006.

AOAC. Official methods of analysis of the Association of Official Analytical Chemists. 18.ed. Gaithersburg, Maryland: AOAC, 2005. cap. 50, met. 985.35 e 984.27, p.15-18.

BORGES, M.F.; FUKUDA, W.M.G.; ROSSETTI, A.G. Avaliação de variedade de mandioca para consumo humano. Pesquisa Agropecuária Brasileira, v.37, n.11, p.1559-1565, 2002. 
CARVALHO, C.R.L. Determinação de isômeros geométricos de alguns carotenóides provitamínicos A por cromatografia líquida de alta eficiência. 1996. 127f. Dissertação (Mestrado em Química) - Instituto de Química da Universidade Estadual de Campinas, Campinas (SP).

CARVALHO C.R.L.; MANTOVANI, D.M.B.; CARVALHO, P.R.N.; MORAES, R.M. Análises químicas de alimentos. Campinas: ITAL, 1990. 121p. (Manual Técnico)

CARVALHO, P.R.N.; SILVA, M.G.; CARVALHO, C.R.L.; VALLE, T.L; CASTRO; J.V.; FELTRAN, J.C. Cor e carotenóides provitamínicos em raízes de diferentes clones de mandioca (Manihot esculenta crantz). In: CONGRESSO BRASILEIRO DE MANDIOCA, 11., 2005. Campo Grande. Anais... Embrapa Agropecuária Oeste, 2005. (CD-Rom)

CHÁVEZ, A.L.; SÁNCHEZ, T.; JARAMILLO, G.; BEDOYA, J.M.; ECHEVERRY, J.; BOLANOS, E.A.; CEBALLOS, H.; IGLESIAS, C.A. Variation of quality traits in cassava roots evaluated in landraces and improved clones. Euphytica, v.143, p.125-133, 2005.

ESSERS, A. J. A., BOSVELD, M., VAN DER GRIFT, R. M., VORAGEN, A. G. J. Studies on the quantification of specific cyanogens in cassava products and introduction of a new chromogen. Journal Science Food Agriculture, v.63, n.3, p.287296, 1993.

FAO. ORGANIZACIÓN DE LAS NACIONES UNIDAS PARA LA AGRICULTURA Y LA ALIMENTACIÓN. Disponível em <http:/ / faostat.fao.org/faostat>. Acesso em 5 de maio de 2005.

FUKUDA, W.M.G.; BORGES, M.F. Avaliação qualitativa de cultivares de mandioca de mesa. Revista Brasileira de Mandioca, v.7, n.1, p.63-71, 1988.

IGLESIAS, C.; MAYEN, J.; CHÁVEZ, L.; CALLE, F. Genetic potential and stability of carotene content in cassava roots. Euphytica, v.94, p. 367-373, 1997.

LORENZI, J.O. Variação na qualidade culinária das raízes de mandioca. Bragantia, v.53, n.2, p.237-245, 1994.

LORENZI, J.O. Mandioca. CATI: Campinas, 116 p., 2003. (Boletim Técnico, 245).

LORENZI, J.O.; DIAS, C.A.C. de. Cultura da mandioca. CATI: Campinas, 41 p., 1993. (Boletim Técnico, 211).

LORENZI, J.O.; VALLE, T.L. IAC 576-A variedade de mandioca de mesa mais cultivada no Estado de São Paulo. Campinas: Instituto Agronômico (IAC), 2002. 4 p. (Fôlder)

MEZETTE, T.F. Seleção de variedades de mandioca de mesa (Manihot esculenta Crantz) com altos teores de carotenóides e vitamina A. 2007. 54f. Dissertação (Mestrado em Agricultura Tropical e Subtropical) - Instituto Agronômico, Campinas (SP).

MKUMBIRA, J.; CHIWONA-KARLTUN, L.; LANGERCRANTZ, U.; MAHUNGU, N.M.; SAKA, J.; MHONE, A.; BOKANGA, M.; BRIMER, L.; GULLBERG, U.; ROSLING, H. Classification of cassava into 'bitter' and 'cool' in Malawi: From farmers' perception to characterisation by molecular markers. Euphytica, v.132, p.7-22, 2003.
OMS. ORGANIZAÇÃO MUNDIAL DA SAÚDE. Disponível em http://www.who.int/nut/vad.htm. Acesso em 14 de janeiro de 2006.

ORTEGA-FLORES, C.I. Carotenóides com atividade próvitamínica $\mathrm{A}$ e teores de cianeto em diferentes cultivadores de mandioca (Manihot esculenta Crantz) do estado de São Paulo. 1991. 77f. Dissertação (Mestrado em Ciências dos Alimentos) - Faculdade de Ciências Farmacêuticas da Universidade de São Paulo, São Paulo.

PENTEADO, M.V.C. Ocorrência de isômeros de â-caroteno em raízes de cinco cultivares de mandioca (Manihot esculenta Crantz) do Estado de São Paulo. 1987. 66 f. Tese (Concurso de Livre-Docência) - Departamento de Alimentos e Nutrição Experimental da Faculdade de Ciências Farmacêuticas da Universidade de São Paulo, São Paulo.

PEREIRA, A.S.; LORENZI, J.O.; VALLE, T.L. Avaliação do tempo de cozimento e padrão de massa cozida em mandioca de mesa. Revista Brasileira de Mandioca, v.4, n.1, p.27-32, 1985.

RAMALHO, A.; SAUNDERS, C.; ACCIOLY, E. Novos grupos de risco para a deficiência de vitamina A. Disponível em: http:/ /www.comunique-se.com.br/produtos/saladeimprensa/ $\begin{array}{lllllllllll}\mathrm{p} & \mathrm{r} & \mathrm{e} & \mathrm{m} & \mathrm{i} & \mathrm{o} & \mathrm{w} & \mathrm{y} & \mathrm{e} & \mathrm{t} & \mathrm{h}\end{array}$ artigo_novos_grupos_de_riscos_para_deficiencia_de_vitamina_a.pdf. Acesso em 13 de dezembro de 2006.

RIMOLDI, F.; VIDIGAL FILHO, P.S., VIDIGAL, M.C.G.; CLEMENTE, E.; PEQUENO, M.G.; MIRANDA, L.; KVITSCHAL, M.V. Produtividade, composição química e tempo de cozimento de cultivares de mandioca de mesa coletadas no Estado do Paraná. Acta Scientia Agraria, v.28, n.1, p.63-69, 2006.

RONCADA, M.S. Vitaminas Lipossolúveis, In: DUTRA-DEOLIVEIRA J.E.; MARCHINI, J.S. Ciências Nutricionais. São Paulo: Sarvier, 1998. p.167-189.

VALLE, T.L.;CARVALHO,C. R. L.; RAMOS, M. T. B.;MÜHLEN, G.S.; VIEIRA, O. V. Conteúdo cianogênico em progênies de mandioca originadas do cruzamento de variedades mansas e bravas. Bragantia, v.63, n.2, p.221-226, 2004

WELCH, R.M.; GRAHAM, R.D. Breeding crops for enhanced micronutrient content. Plant and Soil, v.245, p.205-214, 2002.

ZANCUL M.S. Fortificação de alimentos com ferro e vitamina A. Medicina, v.37, p. 45-50, 2004. 